\section{Indicadores de segurança do paciente para hospitais de pacientes agudos: revisão sistemática}

\author{
Patient safety indicators for acute care hospitals: \\ a systematic review
}

1 Instituto de Medicina Social, Universidade do Estado do Rio de Janeiro, Rio de Janeiro, Brasil.

2 Instituto de Comunicação

e Informação Científica e Tecnológica em Saúde, Fundação Oswaldo Cruz, Rio de Janeiro, Brasil.

Correspondência C. S. D. Gouvêa Instituto de Medicina Social, Universidade do Estado do Rio de Janeiro.

Rua São Francisco Xavier 524, Pavilhão João Lyra Filho, 7 a andar, Rio de Janeiro, $R J$ 20550-900, Brasil.

cdgouvea@gmail.com

\section{Abstract}

A systematic review was conducted to identify the strategies used in the development of patient safety indicators for acute care hospitals. The data sources were MEDLINE, EMBASE, websites, and reference lists from articles and documents. Fourteen projects on the development of indicators were included. The review showed the use of different terms with varying definitions of quality and patient safety. The literature review and participation by specialists and other stakeholders characterized the projects. Of the 285 identified indicators, 125 were classified in more than one quality dimension. The most frequent combination was safety and effectiveness. Most were medication indicators, and more than half were outcome indicators. In developing patient safety indicators, the results show the importance of considering variations in culture and medical practice, the availability of information systems, and the capacity of hospitals and health systems to implement effective monitoring systems.

Safety; Health Care Quality Indicators; Hospitalization
Carla Simone Duarte de Gouvêa 1

Claudia Travassos 2

\section{Introdução}

Cuidados de saúde inseguros resultam em expressiva morbidade e mortalidade evitáveis, gastos adicionais com a manutenção dos sistemas de saúde e representam uma grande preocupação na atualidade 1. Estudos em hospitais de vários países mostram a associação entre a ocorrência de eventos adversos, incidentes que ocasionam danos aos pacientes 2 , e o aumento do tempo de permanência, da mortalidade e do gasto hospitalar 3,4. Estimativas dos países desenvolvidos indicam que pelo menos $5 \%$ dos pacientes admitidos em hospitais contraem uma infecção 1. No Brasil, pesquisa recente em três hospitais de ensino do Rio de Janeiro identificou uma incidência de $7,6 \%$ de pacientes com eventos adversos, sendo $66,7 \%$ destes com eventos adversos evitáveis 5 . Esse contexto incentivou na última década a promoção de diferentes iniciativas para garantir cuidados de saúde mais seguros 6,7. Dentre elas, destaca-se a criação de programas para o monitoramento da qualidade e segurança com base em indicadores.

A qualidade do cuidado em saúde é definida pela Organização Mundial da Saúde (OMS) como "o grau em que os serviços de saúde para indivíduos e populações aumentam a probabilidade de resultados desejados e são consistentes com o conhecimento profissional atual" 2 (p. 22). A segurança é uma importante dimensão da qualidade que se refere ao direito das pessoas de terem o 
"risco de um dano desnecessário associado com o cuidado de saúde reduzido a um mínimo aceitável" 2 (p. 21). Erros, violações e falhas no processo de cuidado aumentam o risco de incidentes que causam danos aos pacientes 2 .

A qualidade é um conceito multidimensional, que requer diferentes abordagens para a sua avaliação. Indicador de qualidade pode ser definido como uma medida quantitativa sobre algum aspecto do cuidado ao paciente ${ }^{8}$. Seu uso permite o monitoramento do desempenho dos serviços de saúde, a programação de ações de melhoria de qualidade e orienta os pacientes para que realizem escolhas mais bem informadas. A utilidade dos indicadores depende de sua validade, confiabilidade e viabilidade 8,9,10.

Os hospitais são responsáveis por significativa e complexa parcela dos cuidados de saúde prestados aos pacientes. A inclusão de indicadores de segurança nos programas de monitoramento da qualidade representa uma importante estratégia para orientar medidas que promovam a segurança do paciente hospitalizado. No Brasil, ainda não existe um conjunto de indicadores definidos com essa finalidade, além de serem escassas as pesquisas sobre o tema.

O objetivo desta revisão é identificar as estratégias para o desenvolvimento de indicadores de segurança do paciente em hospitais, a fim de contribuir para o desenvolvimento de um conjunto de medidas de segurança adaptadas à realidade brasileira.

\section{Método}

Realizou-se uma revisão sistemática da literatura sobre as estratégias utilizadas no desenvolvimento de indicadores de segurança do paciente para hospitais de pacientes agudos. A busca eletrônica utilizou as seguintes fontes: MEDLINE, por meio da interface do PubMed, e EMBASE. O período coberto pelo estudo foi de 2002 a 2008. Selecionaram-se no MEDLINE 45 artigos sobre segurança do paciente. Os Medical Subject Heading Terms (MeSH) utilizados para indexá-los foram a base para compor a equação de busca, posteriormente adaptada para o EMBASE (Tabela 1).

Os critérios de seleção dos artigos incluíram aqueles que: (a) descreveram o processo utilizado no desenvolvimento dos indicadores e (b) realizaram desenvolvimento de indicadores específicos de segurança do paciente ou mencionaram a segurança como uma das dimensões de avaliação. Não foram feitas restrições quanto à idade dos pacientes, problema de saúde ou setor do hospital. Os critérios de exclusão foram: (a) apresentar unicamente indicadores para unidades de cuidados prolongados ou cuidados a pacientes externos e (b) apresentar indicadores/ eventos referidos a sistemas de notificação e de vigilância 11. Não foram selecionados textos no formato de: cartas, editoriais, notícias, comentários de profissionais, estudos de caso e artigos sem resumo. Apenas documentos com versão para o português, inglês ou espanhol foram incluídos na revisão.

Para complementar a pesquisa eletrônica, foi feita busca manual de documentos em sítios na Internet. Também se procedeu à verificação das referências bibliográficas dos artigos e dos documentos incluídos na revisão. Diversos artigos e documentos referiam-se a um único projeto de desenvolvimento de indicadores. O projeto foi considerado como a unidade de análise desta revisão.

Os sítios pesquisados restringiram-se àqueles citados pelos projetos incluídos na revisão e que representassem organizações de âmbito nacional ou internacional (Tabela 2). No interior dos sítios, foi feita uma busca direcionada nas seções de publicações ou nas páginas dirigidas à segurança do paciente e a indicadores. Não foram utilizados os campos de busca nem a seção de links. Informação complementar sobre os projetos incluídos também foi pesquisada nos seus respectivos sítios na Internet.

Os títulos e os resumos dos artigos recuperados na busca eletrônica foram avaliados de forma independente por dois revisores, aplicando os critérios de inclusão e exclusão; as divergências foram resolvidas por consenso. A pesquisa nos sítios da Internet, a verificação das referências bibliográficas e a leitura completa dos textos selecionados foram feitas exclusivamente por uma das autoras, utilizando os mesmos critérios de inclusão e exclusão.

As variáveis do estudo foram: país(es) onde o projeto foi desenvolvido, organização(ões) envolvida(s), ano do estudo e descrição/ objetivo(s); modelo conceitual, métodos e critérios para seleção e validação dos indicadores; título do indicador, fonte dos dados, nível da informação e dimensão(ões) da qualidade. Para a coleta dos dados, foi desenvolvido um formulário padrão, elaborado com base na análise da literatura sobre desenvolvimento de indicadores 9,10,12, que foi pré-testado com três projetos.

Com o propósito de quantificar o total de indicadores obtidos, estes foram agregados quando nenhuma diferença nas especificações (numerador, denominador, população-alvo e período de tempo para a medida) foi identificada. Quando variações foram observadas, eles foram contabilizados individualmente. Os indicadores 


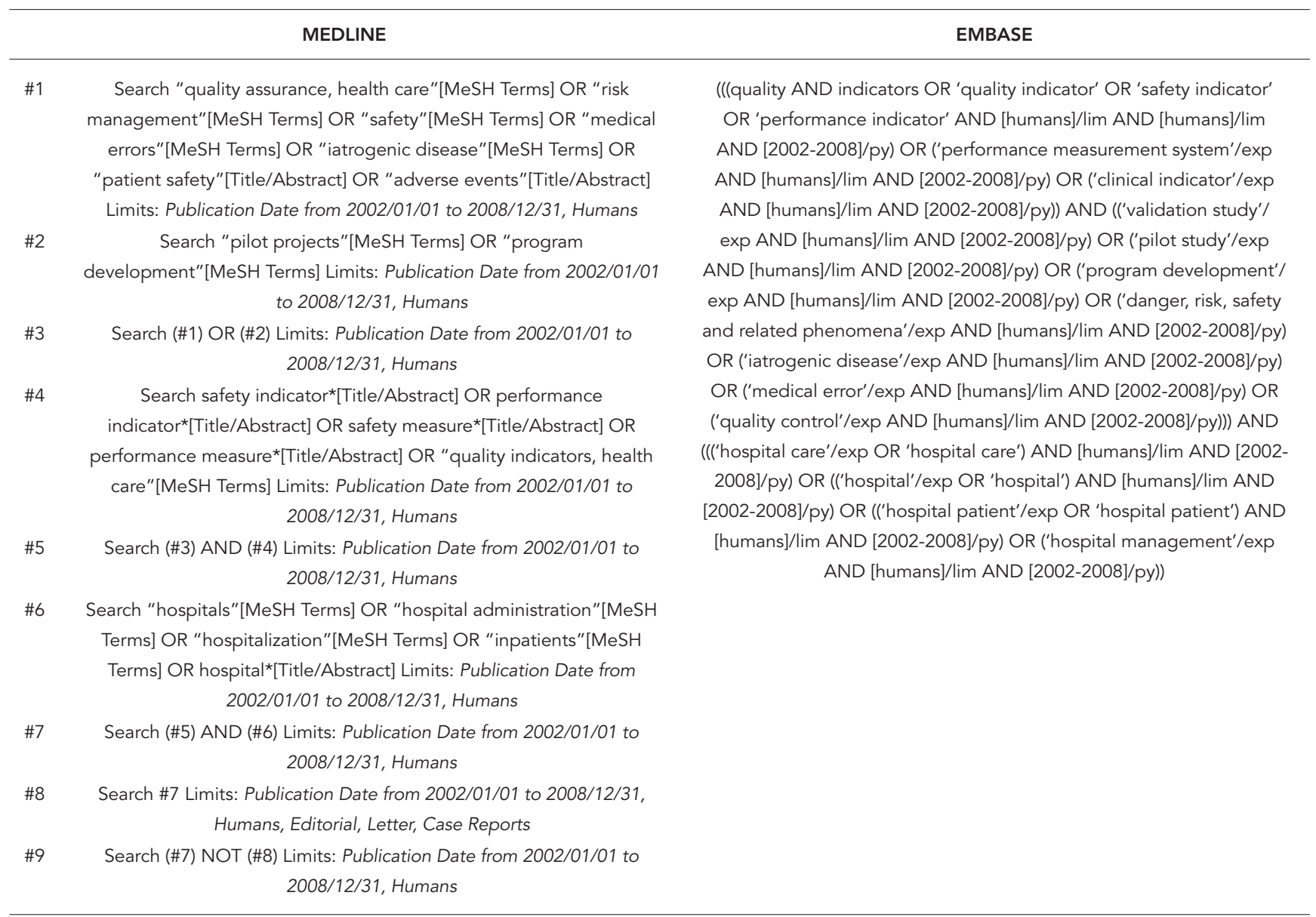

também foram classificados por áreas clínicas ou setor de cuidado, a saber: clínicos; cirurgia/anestesia; unidade de cuidados intensivos (UTI) para adultos; UTI pediátricas; obstetrícia/ginecologia; controle de infecção; uso de medicamentos; outros (inclui indicadores não classificados nos itens anteriores). Buscou-se agrupar os indicadores de acordo com a população abrangida: crianças (menores de 18 anos) e adultos. Quando o indicador se referia a práticas ou processos aplicáveis às duas faixas etárias, eles foram agrupados na categoria "ambos". No caso de indicadores que podiam ser agrupados em mais de uma área, optou-se por classificá-los naquela onde os processos clínicos fossem mais especializados. Por exemplo: o indicador "Infecções relacionadas a cateter venoso central em UTI de adulto" foi classificado na categoria UTI adulto e não na de infecções. Os indicadores também foram classificados segundo o nível da informa- ção (estrutura, processo e resultado), fornecida pela organização desenvolvedora. Quando essa informação não estava disponível, os critérios desenvolvidos por Donabedian 13 foram utilizados para classificá-los.

\section{Resultados}

Um total de 2.047 artigos e documentos foi identificado na revisão (1.950 mediante pesquisa eletrônica, 55 nas referências bibliográficas e 42 nos sítios na Internet). Desses, 142 foram selecionados para leitura completa do texto e 47 foram incluídos no estudo, referentes a 14 projetos. Oito projetos foram recuperados por intermédio da pesquisa eletrônica $14,15,16,17,18,19,20,21$, quatro em sítios da Internet 22,23,24,25 e dois nas referências bibliográficas 26,27. Quatro projetos são dos Estados Unidos 14,15,19,20, três da Austrália 23,25,27, 
Tabela 2

Sítios na Internet acessados e endereços eletrônicos.

\begin{tabular}{|c|c|}
\hline Nome & Endereço eletrônico \\
\hline Agency for Healthcare Research an Quality (AHRQ) Patient Safety Indicators (PSIs) & http://www.qualityindicators.ahrq.gov/psi_overview.htm \\
\hline Australian Commission on Safety and Quality in Health Care (ACSQ) & http://www.safetyandquality.gov.au/ \\
\hline Australian Institute of Health and Welfare (AIHW) & http://www.aihw.gov.au/ \\
\hline Canadian Institute for Health Information (CIHI) & http://secure.cihi.ca/ \\
\hline Canadian Patient Safety Institute (CPSI) & http://www.patientsafetyinstitute.ca/ \\
\hline National Association of Children's Hospitals and Related Institutions (NACHRI) & http://www.childrenshospitals.net/ \\
\hline National Quality Forum (NOF) & http://www.qualityforum.org/ \\
\hline Organisation for Economic Co-operation and Development (OECD) - HCQI & http://www.oecd.org/health/hcqi \\
\hline Performance Assessment Tool for Quality Improvement in Hospitals (PATH) & http://www.pathqualityproject.eu/ \\
\hline Quality Indicator Project (QiP) & http://www.qiproject.org/ \\
\hline Safety Improvement for Patients in Europe (SimPatIE) & http://www.simpatie.org/Main \\
\hline The Australian Council on Healthcare Standards (ACHS) & http://www.achs.org.au/ \\
\hline The Danish National Indicator Project & http://www.nip.dk/ \\
\hline The Joint Commission & http://www.jointcommission.org/ \\
\hline The Netherlands Health Care Inspectorate (NHCl) & http://www.igz.nl/uk/ \\
\hline The Royal Australasian College of Physicians & http://www.racp.edu.au/ \\
\hline $\begin{array}{l}\text { The Royal Australian and New Zealand College of Obstetricians and Gynaecologists } \\
\text { (RANZCOG) }\end{array}$ & http://www.ranzcog.edu.au/ \\
\hline World Health Organization (WHO) Regional Office for Europe & http://www.euro.who.int/publications \\
\hline
\end{tabular}

dois do Canadá 21,22 e um da Holanda 16. Em um projeto existe co-participação de organizações da Austrália e Nova Zelândia 26 e três envolvem vários países liderados pelas seguintes organizações: World Health Organization Regional Office for Europe (WHO/EURO) 17, Organization for Economic Co-operation and Development (OECD) 18 e ESQH-Office for Quality Indicators in Aarhus, Dinamarca 24 (Tabela 3).

Apenas quatro projetos tiveram como objetivo desenvolver especificamente indicadores de segurança do paciente: o estudo da organização americana Agency for Healthcare Research an Quality (AHRQ) 14, o da organização internacional OECD 18 e o projeto Safety Improvement for Patients in Europe (SimPatIE), do European Society for Quality in Healthcare (ESQH) 24. O quarto é um estudo canadense voltado para a área de medicamentos 21 .

Nos demais projetos a segurança foi abordada como uma das dimensões de qualidade $15,16,17,19,20,22,23,25,26,27$. Quatro são iniciativas nacionais $16,22,25$ e internacionais 17 para monitorar o desempenho e a qualidade de sistemas e organizações de saúde. Cinco dirigiram-se para setores ou populações específicas: UTI de pacientes adultos 15 , UTI pediátricas 19 , crianças 20 , maternidades 23 e medicamentos 27 . E um projeto cor- responde a uma iniciativa de desenvolvimento e revisão contínua de indicadores vinculados ao processo de acreditação de uma agência nacional australiana 26 .

\section{Processo de desenvolvimento dos indicadores}

\section{- Modelo conceitual}

Onze projetos $14,15,17,18,20,24,25,27,28,29,30$ apresentaram definição de segurança ou segurança do paciente. Embora com variações, as definições incluem em seu contexto a noção comum de redução do risco de danos aos pacientes ocasionado pela atenção à saúde, como, por exemplo, a definição de segurança adotada pelo Canadá: "os riscos potenciais de uma intervenção ou do ambiente são evitados ou minimizados" 29. Embora restrito ao âmbito dos hospitais, o conceito segurança do projeto Performance Assessment Tool for Quality Improvement in Hospitals (PATH) 17 (p. 490) é o que aborda um contexto mais amplo, incluindo a segurança de pacientes, das equipes e do ambiente, sendo assim definido: "dimensão do desempenho, onde o hospital tem a estrutura apropriada e usa os processos de cuidados que previnem ou reduzem danos ou riscos aos 
Tabela 3

Características dos projetos incluídos na revisão sistemática.

\begin{tabular}{|c|c|c|c|c|c|c|c|c|c|}
\hline \multirow[t]{2}{*}{ Autor } & \multirow[t]{2}{*}{ Ano } & \multirow[t]{2}{*}{ Países } & \multirow{2}{*}{$\begin{array}{l}\text { Organi- } \\
\text { zações }\end{array}$} & \multirow[t]{2}{*}{ Ano } & \multirow{2}{*}{$\begin{array}{l}\text { Descrição/ } \\
\text { Objetivo(s) }\end{array}$} & \multicolumn{4}{|c|}{ Desenvolvimento } \\
\hline & & & & & & Modelo conceitual & $\begin{array}{c}\text { Métodos para } \\
\text { seleção e } \\
\text { validação }\end{array}$ & $\begin{array}{c}\text { Critérios para } \\
\text { seleção }\end{array}$ & $\begin{array}{l}\text { Quantidade de } \\
\text { indicadores * }\end{array}$ \\
\hline ACHS 26 & 2007 & $\begin{array}{l}\text { Austrália } \\
\text { e Nova } \\
\text { Zelândia }\end{array}$ & $\begin{array}{l}\text { ACHS e } \\
\text { Australian } \\
\text { and New } \\
\text { Zealand } \\
\text { Medical } \\
\text { Colleges }\end{array}$ & $\begin{array}{c}\text { Início em } \\
1989 \\
\text { (revisto } \\
\text { anual- } \\
\text { mente) }\end{array}$ & $\begin{array}{l}\text { O conjunto de } \\
\text { indicadores } \\
\text { é parte do } \\
\text { processo de } \\
\text { acreditação da } \\
\text { ACHS }\end{array}$ & $\begin{array}{l}\text { Dimensões de } \\
\text { desempenho } \\
\text { do sistema de } \\
\text { saúde australiano: } \\
\text { (efetividade, } \\
\text { adequação; } \\
\text { capacidade } \\
\text { de resposta } \\
\text { ["responsive"], } \\
\text { acessibilidade, } \\
\text { segurança, } \\
\text { continuidade, } \\
\text { capacidade e } \\
\text { sustentabili- } \\
\text { dade) } 28,33\end{array}$ & $\begin{array}{c}\text { Revisão de } \\
\text { literatura; grupos } \\
\text { de trabalho com } \\
\text { especialistas } \\
\text { e outros } \\
\text { stakeholders; } \\
\text { endosso por } \\
\text { organizações } \\
\text { profissionais; } \\
\text { e revisão pela } \\
\text { ACHS }\end{array}$ & $\begin{array}{l}\text { Revisão anual } \\
\text { para garantir } \\
\text { relevância, } \\
\text { consenso nos } \\
\text { requisitos } \\
\text { para coleta de } \\
\text { dados e relato, } \\
\text { utilidade para } \\
\text { a melhoria de } \\
\text { qualidade; } \\
\text { refletir o } \\
\text { ambiente de } \\
\text { cuidados atual }\end{array}$ & $12426,46,47,48$ \\
\hline $\mathrm{ClHI} 22$ & 2005 & Canadá & $\mathrm{ClHI}$ & $\begin{array}{l}\text { Início } \\
\text { em } 1999 \\
\text { (revisão } \\
\text { 2004) }\end{array}$ & $\begin{array}{l}\text { Apoiar as regiões } \\
\text { no monitora- } \\
\text { mento do fun- } \\
\text { cionamento do } \\
\text { sistema de saúde } \\
\text { e melhoria da } \\
\text { saúde da popu- } \\
\text { lação }\end{array}$ & $\begin{array}{l}\text { Dimensões de } \\
\text { desempenho do } \\
\text { sistema de saúde } \\
\text { canadense: segu- } \\
\text { rança, efetividade, } \\
\text { adequação, eficiên- } \\
\text { cia, acessibilidade, } \\
\text { continuidade, } \\
\text { competência e } \\
\text { aceitabilidade. } \\
\text { Equidade; dimen- } \\
\text { são transversa }\end{array}$ & $\begin{array}{l}\text { Grupo consultor; } \\
\text { revisão de pro- } \\
\text { gramas seme- } \\
\text { Ihantes; opinião } \\
\text { de especialistas } \\
\text { e outros stake- } \\
\text { holders; Técnica } \\
\text { de Delphi; duas } \\
\text { Conferências } \\
\text { Nacionais de } \\
\text { Consenso 22,29 }\end{array}$ & $\begin{array}{l}\text { Relevância; acor- } \\
\text { dados com base } \\
\text { em critérios/ori- } \\
\text { entações; coleta } \\
\text { a partir de mé- } \\
\text { todos/definições } \\
\text { padronizadas e } \\
\text { fontes confiáveis; } \\
\text { e viabilidade nas } \\
\text { regiões de saúde }\end{array}$ & $\begin{array}{c}1 \text { ( } 6 \text { em } \\
\text { desenvolvi- } \\
\text { mento) } 22,29\end{array}$ \\
\hline $\begin{array}{l}\text { Romano } \\
\text { et al. } 14\end{array}$ & 2003 & $\begin{array}{l}\text { Estados } \\
\text { Unidos }\end{array}$ & AHRQ & 2002 & $\begin{array}{l}\text { Os PSI formam o } \\
\text { terceiro conjunto } \\
\text { de indicadores } \\
\text { de qualidade } \\
\text { desenvolvidos } \\
\text { pela AHRQ, } \\
\text { para uso em } \\
\text { bancos de dados } \\
\text { administrativos }\end{array}$ & $\begin{array}{c}\text { Desenvolvida } \\
\text { uma matriz } \\
\text { conceitual para } \\
\text { avaliar potenciais } \\
\text { indicadores e } \\
\text { padronizadas } \\
\text { definições de } \\
\text { termos mais } \\
\text { usados } 14,31\end{array}$ & $\begin{array}{l}\text { Revisão de litera- } \\
\text { tura; revisão por } \\
\text { especialista em } \\
\text { CID-9-CM; aná- } \\
\text { lise de dados; } \\
\text { Delphi modifi- } \\
\text { cado. Piloto em } \\
\text { desenvolvimen- } \\
\text { to, para analisar } \\
\text { a validade de } \\
\text { critério } 42\end{array}$ & $\begin{array}{c}\text { Utilidade; } \\
\text { probabilidade } \\
\text { de o indicador } \\
\text { medir } \\
\text { complicação } \\
\text { e não } \\
\text { comorbidades; } \\
\text { grau em que } \\
\text { a complicação } \\
\text { é evitável e } \\
\text { devida a erros; } \\
\text { probabilidade } \\
\text { de que a } \\
\text { complicação } \\
\text { seja registrada; } \\
\text { e grau em que } \\
\text { o indicador está } \\
\text { sujeito a viés } 31\end{array}$ & $\begin{array}{l}20 \text { PSI no nível do } \\
\text { prestador (destes, } \\
7 \text { são também } \\
\text { definidos para } \\
\text { uso em uma área } \\
\text { determinada); } \\
1 \text { indicador } \\
\text { composto } 14,31,49,50\end{array}$ \\
\hline
\end{tabular}

(continua) 
Tabela 3 (continuação)

\begin{tabular}{|c|c|c|c|c|c|c|c|c|c|}
\hline \multirow[t]{2}{*}{ Autor } & \multirow[t]{2}{*}{ Ano } & \multirow[t]{2}{*}{ Países } & \multirow{2}{*}{$\begin{array}{l}\text { Organi- } \\
\text { zações }\end{array}$} & \multirow[t]{2}{*}{ Ano } & \multirow{2}{*}{$\begin{array}{l}\text { Descrição/ } \\
\text { Objetivo(s) }\end{array}$} & \multicolumn{4}{|c|}{ Desenvolvimento } \\
\hline & & & & & & Modelo conceitual & $\begin{array}{c}\text { Métodos para } \\
\text { seleção e } \\
\text { validação }\end{array}$ & $\begin{array}{c}\text { Critérios para } \\
\text { seleção }\end{array}$ & $\begin{array}{c}\text { Quantidade de } \\
\text { indicadores * }\end{array}$ \\
\hline $\begin{array}{l}\text { Beren- } \\
\text { holtz et } \\
\text { al. } 15\end{array}$ & 2002 & $\begin{array}{l}\text { Estados } \\
\text { Unidos }\end{array}$ & $\begin{array}{l}\text { Johns } \\
\text { Hopkins } \\
\text { University } \\
\text { Schools } \\
\text { of } \\
\text { Medicine } \\
\text { and } \\
\text { Hygiene } \\
\text { and } \\
\text { Public } \\
\text { Health e } \\
\text { Volunteer } \\
\text { Hospitals } \\
\text { of } \\
\text { America, } \\
\text { Inc. }\end{array}$ & 2002 & $\begin{array}{l}\text { Identificar } \\
\text { intervenções } \\
\text { que melhoram } \\
\text { os resultados } \\
\text { dos cuidados em } \\
\text { UTI para adultos } \\
\text { e selecionar } \\
\text { indicadores de } \\
\text { qualidade que } \\
\text { possam melhorar } \\
\text { esses cuidados. }\end{array}$ & $\begin{array}{c}\text { Dimensões do } \\
\text { IOM } 32 \text { (segurança, } \\
\text { efetividade, } \\
\text { cuidados centrados } \\
\text { no paciente, } \\
\text { oportunidade do } \\
\text { cuidado, eficiência } \\
\text { e equidade) }\end{array}$ & $\begin{array}{c}\text { Revisão de } \\
\text { literatura; } \\
\text { opinião de } \\
\text { especialistas; } \\
\text { grupo nominal. } \\
\text { Piloto em } 13 \\
\text { UTIs, para avaliar } \\
\text { a validade } \\
\text { (construto e } \\
\text { conteúdo) e } \\
\text { confiabilidade } 37\end{array}$ & $\begin{array}{c}\text { Impacto } \\
\text { potencial na } \\
\text { morbidade, } \\
\text { mortalidade } \\
\text { e custos; } \\
\text { viabilidade; } \\
\text { variabilidade; } \\
\text { capacidade do } \\
\text { prestador de ter } \\
\text { impacto sob o } \\
\text { indicador; força } \\
\text { da evidência }\end{array}$ & 12 \\
\hline $\begin{array}{l}\text { Berg et } \\
\text { al. } 16\end{array}$ & 2005 & Holanda & $\begin{array}{l}\text { CBO, } \\
\text { Dutch } \\
\text { Health } \\
\text { Care } \\
\text { Inspec- } \\
\text { torate e } \\
\text { Institute } \\
\text { for Public } \\
\text { Health } \\
\text { and Envi- } \\
\text { ronment }\end{array}$ & 2003 & $\begin{array}{l}\text { Desenvolver } \\
\text { um conjunto de } \\
\text { indicadores de } \\
\text { desempenho } \\
\text { hospitalar, } \\
\text { públicos e } \\
\text { obrigatórios, } \\
\text { englobando } \\
\text { a segurança } \\
\text { do paciente e } \\
\text { a efetividade } \\
\text { clínica }\end{array}$ & $\begin{array}{c}\text { O projeto } \\
\text { tem princípios } \\
\text { norteadores: } \\
\text { permitir uma } \\
\text { primeira análise } \\
\text { dos cuidados } \\
\text { prestados por } \\
\text { cada hospital; } \\
\text { aumentar a } \\
\text { transparência desse } \\
\text { setor; estimular } \\
\text { a melhoria de } \\
\text { qualidade }\end{array}$ & $\begin{array}{l}\text { Revisão de } \\
\text { literatura; } \\
\text { reuniões com } \\
\text { especialistas } \\
\text { e outros } \\
\text { stakeholders. } \\
\text { Piloto em } 6 \\
\text { hospitais }\end{array}$ & $\begin{array}{c}\text { Indicador } \\
\text { de resultado } \\
\text { ou "proxy"; } \\
\text { prevalência; } \\
\text { potencial para } \\
\text { melhorar a } \\
\text { qualidade; } \\
\text { conexão clara e } \\
\text { oportuna com } \\
\text { as atividades de } \\
\text { cuidado; geração } \\
\text { de resultados } \\
\text { desejáveis; } \\
\text { facilidade de } \\
\text { implementação }\end{array}$ & 2816,51 \\
\hline $\begin{array}{l}\text { Veillard et } \\
\text { al. } 17\end{array}$ & 2005 & $\begin{array}{l}\text { Vários } \\
\text { países }\end{array}$ & $\begin{array}{l}\text { WHO/ } \\
\text { EURO }\end{array}$ & 2003 & $\begin{array}{c}\text { Apoiar os } \\
\text { hospitais na } \\
\text { avaliação de } \\
\text { desempenho e } \\
\text { implementação } \\
\text { de melhorias, } \\
\text { além de permitir } \\
\text { comparações } \\
\text { nacionais e } \\
\text { internacionais }\end{array}$ & $\begin{array}{c}\text { Dimensões: } \\
\text { efetividade clínica, } \\
\text { governança } \\
\text { ("responsive } \\
\text { governance"); } \\
\text { orientação da } \\
\text { equipe e eficiência. } \\
\text { Duas dimensões } \\
\text { transversais } \\
\text { às anteriores: } \\
\text { cuidados centrados } \\
\text { no paciente e } \\
\text { segurança }\end{array}$ & $\begin{array}{c}\text { Revisão de } \\
\text { literatura; } \\
\text { opinião de } \\
\text { especialistas; } \\
\text { inquérito em } \\
11 \text { países } \\
\text { para analisar a } \\
\text { relevância dos } \\
\text { indicadores } \\
\text { e o trabalho } \\
\text { necessário para } \\
\text { a coleta dos } \\
\text { dados; grupo } \\
\text { nominal. Piloto } \\
\text { em } 51 \text { hospitais } \\
\text { de } 6 \text { países } 39,52\end{array}$ & $\begin{array}{l}\text { (1) Conjunto } \\
\text { de indicadores: } \\
\text { validade de } \\
\text { face, conteúdo } \\
\text { e construto; (2) } \\
\text { Indicadores: } \\
\text { importância } \\
\text { e relevância, } \\
\text { potencial para o } \\
\text { uso, sensível à } \\
\text { implementação; } \\
\text { (3) Instrumento } \\
\text { de medida: } \\
\text { confiabilidade; } \\
\text { validade de } \\
\text { face, conteúdo } \\
\text { e construto; } \\
\text { problemas para } \\
\text { coleta de dados }\end{array}$ & $917,36,52$ \\
\hline
\end{tabular}

(continua) 
Tabela 3 (continuação)

\begin{tabular}{|c|c|c|c|c|c|c|c|c|c|}
\hline \multirow[t]{2}{*}{ Autor } & \multirow[t]{2}{*}{ Ano } & \multirow[t]{2}{*}{ Países } & \multirow{2}{*}{$\begin{array}{l}\text { Organi- } \\
\text { zações }\end{array}$} & \multirow[t]{2}{*}{ Ano } & \multirow{2}{*}{$\begin{array}{l}\text { Descrição/ } \\
\text { Objetivo(s) }\end{array}$} & \multicolumn{4}{|c|}{ Desenvolvimento } \\
\hline & & & & & & Modelo conceitual & $\begin{array}{l}\text { Métodos para } \\
\text { seleção e } \\
\text { validação }\end{array}$ & $\begin{array}{l}\text { Critérios para } \\
\text { seleção }\end{array}$ & $\begin{array}{l}\text { Quantidade de } \\
\text { indicadores * }\end{array}$ \\
\hline $\begin{array}{l}\text { McLoughlin } \\
\text { et al. } 18\end{array}$ & 2006 & $\begin{array}{l}\text { Vários } \\
\text { países }\end{array}$ & OECD & 2004 & $\begin{array}{c}\text { Desenvolver } \\
\text { indicadores em } 5 \\
\text { áreas prioritárias } \\
\text { (cuidado } \\
\text { cardíaco, } \\
\text { diabetes mellitus, } \\
\text { saúde mental, } \\
\text { segurança } \\
\text { do paciente } \\
\text { e promoção/ } \\
\text { prevenção } \\
\text { saúde e atenção } \\
\text { primária) }\end{array}$ & $\begin{array}{c}\text { Modelo } \\
\text { posterior ao } \\
\text { desenvolvimento } \\
\text { dos PSI. Dimensões } \\
\text { de desempenho } \\
\text { do sistema de } \\
\text { saúde: efetividade, } \\
\text { segurança, } \\
\text { cuidados centrados } \\
\text { no paciente } 34\end{array}$ & $\begin{array}{c}\text { Revisão de } \\
\text { indicadores em } \\
\text { uso nos países } \\
\text { membros; } \\
\text { opinião de } \\
\text { especialistas; } \\
\text { Delphi } \\
\text { modificado. } \\
\text { Dois pilotos } \\
\text { para avaliar a } \\
\text { disponibilidade e } \\
\text { comparabilidade } \\
\text { dos dados em } \\
\text { diferentes países } \\
40,41\end{array}$ & $\begin{array}{l}\text { Importância; } \\
\text { força da } \\
\text { evidência } \\
\text { (validade de face } \\
\text { e de conteúdo, } \\
\text { confiabilidade); } \\
\text { viabilidade }\end{array}$ & 1118,53 \\
\hline $\begin{array}{l}\text { Scanlon et } \\
\text { al. } 19\end{array}$ & 2007 & $\begin{array}{l}\text { Estados } \\
\text { Unidos }\end{array}$ & $\begin{array}{l}\text { NACHRI, } \\
\text { CHCA e } \\
\text { Medical } \\
\text { Manage- } \\
\text { ment } \\
\text { Planning, } \\
\text { Inc. }\end{array}$ & 2004 & $\begin{array}{l}\text { Desenvolver } \\
\text { um conjunto } \\
\text { de indicadores } \\
\text { para cuidados } \\
\text { intensivos } \\
\text { pediátricos } \\
\text { e submetê- } \\
\text { los à agencia } \\
\text { americana de } \\
\text { acreditação } \\
\text { (Joint } \\
\text { Commission) }\end{array}$ & $\begin{array}{l}\text { Modelo conceitual } \\
\text { tridimensional } \\
\text { que inclui as } \\
\text { dimensões do } \\
\text { IOM } 32 \text { (segurança, } \\
\text { efetividade, } \\
\text { cuidados centrados } \\
\text { no paciente, } \\
\text { oportunidade do } \\
\text { cuidado, eficiência } \\
\text { e equidade) }\end{array}$ & $\begin{array}{l}\text { Grupo de } \\
\text { especialistas } \\
\text { revisor e } \\
\text { supervisor; } \\
\text { subgrupos com } \\
\text { inclusão de } \\
\text { especialistas } \\
\text { em áreas-chave; } \\
\text { conference } \\
\text { calls; revisão da } \\
\text { literatura }\end{array}$ & $\begin{array}{l}\text { Importância; } \\
\text { força da } \\
\text { evidência } \\
\text { (validade, } \\
\text { confiabilidade } \\
\text { e com base } \\
\text { em evidência } \\
\text { explícita); } \\
\text { viabilidade }\end{array}$ & 230 \\
\hline WHA 23 & 2007 & Austrália & $\begin{array}{l}\text { WHA e } \\
\text { Depart- } \\
\text { ment of } \\
\text { Health, } \\
\text { Western } \\
\text { Australia }\end{array}$ & 2006 & $\begin{array}{l}\text { Estabelecer um } \\
\text { sistema nacional } \\
\text { de forma a } \\
\text { permitir análises } \\
\text { comparativas de } \\
\text { dados clínicos, } \\
\text { para auxiliar } \\
\text { na melhoria da } \\
\text { qualidade e } \\
\text { segurança do } \\
\text { cuidado nas } \\
\text { maternidades }\end{array}$ & $\begin{array}{l}\text { "Modelo de } \\
\text { Qualidade" para } \\
\text { desenvolvimento } \\
\text { dos indicadores } \\
\text { com base nos } \\
\text { ciclos PDSA }\end{array}$ & $\begin{array}{l}\text { Grupo gestor; } \\
\text { grupo de } \\
\text { especialistas; } \\
\text { grupo de } \\
\text { referência; } \\
\text { Técnica de } \\
\text { Delphi; análise } \\
\text { de dados. } \\
\text { Análise por } \\
\text { revisores } \\
\text { independentes }\end{array}$ & $\begin{array}{l}\text { Importância; } \\
\text { praticidade; } \\
\text { aspectos } \\
\text { técnicos (força } \\
\text { científica, } \\
\text { padronização, } \\
\text { representativi- } \\
\text { dade) }\end{array}$ & $\begin{array}{l}4 \text { (classificados na } \\
\text { dimensão seguran- } \\
\text { ça por revisores } \\
\text { independentes) }\end{array}$ \\
\hline
\end{tabular}

(continua) 
Tabela 3 (continuação)

\begin{tabular}{|c|c|c|c|c|c|c|c|c|c|}
\hline \multirow[t]{2}{*}{ Autor } & \multirow[t]{2}{*}{ Ano } & \multirow[t]{2}{*}{ Países } & \multirow{2}{*}{$\begin{array}{l}\text { Organi- } \\
\text { zações }\end{array}$} & \multirow[t]{2}{*}{ Ano } & \multirow{2}{*}{$\begin{array}{l}\text { Descrição/ } \\
\text { Objetivo(s) }\end{array}$} & \multicolumn{4}{|c|}{ Desenvolvimento } \\
\hline & & & & & & Modelo conceitual & $\begin{array}{c}\text { Métodos para } \\
\text { seleção e } \\
\text { validação }\end{array}$ & $\begin{array}{l}\text { Critérios para } \\
\text { seleção }\end{array}$ & $\begin{array}{l}\text { Quantidade de } \\
\text { indicadores * }\end{array}$ \\
\hline $\begin{array}{l}\text { McDonald } \\
\text { et al. } 20\end{array}$ & 2008 & $\begin{array}{l}\text { Estados } \\
\text { Unidos }\end{array}$ & AHRQ & 2006 & $\begin{array}{l}\text { Os PDIs formam } \\
\text { o quarto } \\
\text { conjunto de } \\
\text { indicadores } \\
\text { de qualidade } \\
\text { desenvolvidos } \\
\text { pela AHRO. A } \\
\text { primeira fase } \\
\text { consistiu na } \\
\text { avaliação da } \\
\text { aplicabilidade } \\
\text { dos indicadores } \\
\text { de qualidade à } \\
\text { população de } \\
\text { crianças }\end{array}$ & Não mencionado & $\begin{array}{l}\text { Revisão de } \\
\text { literatura; revisão } \\
\text { por especialista } \\
\text { em CID-9-CM; } \\
\text { análise de } \\
\text { dados; painéis } \\
\text { de especialistas; } \\
\text { Delphi } \\
\text { modificado; e } \\
\text { revisão por pares }\end{array}$ & $\begin{array}{c}\text { Utilidade; } \\
\text { probabilidade } \\
\text { de o indicador } \\
\text { medir } \\
\text { complicação } \\
\text { e não } \\
\text { comorbidades; } \\
\text { grau em que } \\
\text { a complicação } \\
\text { é evitável e } \\
\text { devida a erros; } \\
\text { probabilidade } \\
\text { de que a } \\
\text { complicação } \\
\text { seja registrada; } \\
\text { grau em que o } \\
\text { indicador está } \\
\text { sujeito a viés } 35\end{array}$ & $\begin{array}{c}11 \text { PSI adaptados } \\
\text { para cuidados } \\
\text { pediátricos; } 1 \\
\text { indicador composto } \\
20,35,54,55\end{array}$ \\
\hline $\begin{array}{l}\text { Kristensen } \\
\text { et al. } 24\end{array}$ & 2007 & $\begin{array}{l}\text { Vários } \\
\text { países }\end{array}$ & $\begin{array}{l}\text { Líder: } \\
\text { ESOH- } \\
\text { Office for } \\
\text { Quality } \\
\text { Indicators } \\
\text { in Aarhus; } \\
\text { financia- } \\
\text { do pela } \\
\text { European } \\
\text { Commis- } \\
\text { sion }\end{array}$ & 2007 & $\begin{array}{l}\text { Desenvolver PSI } \\
\text { para hospitais, } \\
\text { e outros } \\
\text { instrumentos, } \\
\text { internos e } \\
\text { externos, para } \\
\text { a melhoria da } \\
\text { segurança do } \\
\text { cuidado em } \\
\text { saúde }\end{array}$ & $\begin{array}{c}\text { A segurança é } \\
\text { considerada uma } \\
\text { dimensão de um } \\
\text { construto mais } \\
\text { amplo da cultura } \\
\text { (abrangendo } \\
\text { aspectos da cultura } \\
\text { organizacional e } \\
\text { clínica) }\end{array}$ & $\begin{array}{c}\text { Revisão da } \\
\text { literatura; } \\
\text { processo formal } \\
\text { de consenso } \\
\text { com reuniões } \\
\text { de especialistas } \\
\text { durante as } \\
\text { fases de } \\
\text { planejamento e } \\
\text { desenvolvimento }\end{array}$ & $\begin{array}{c}\text { Relevância e } \\
\text { adequação; } \\
\text { validade e } \\
\text { confiabilidade; e } \\
\text { viabilidade }\end{array}$ & 1424,56 \\
\hline $\begin{array}{l}\text { Nigam et } \\
\text { al. } 21\end{array}$ & 2008 & Canadá & CPSI & 2007 & $\begin{array}{c}\text { Desenvolver } \\
\text { um conjunto de } \\
\text { indicadores de } \\
\text { segurança para } \\
\text { medicamentos } \\
\text { que possam } \\
\text { ser utilizados } \\
\text { na avaliação } \\
\text { da qualidade } \\
\text { da assistência } \\
\text { hospitalar e em } \\
\text { outros setores }\end{array}$ & 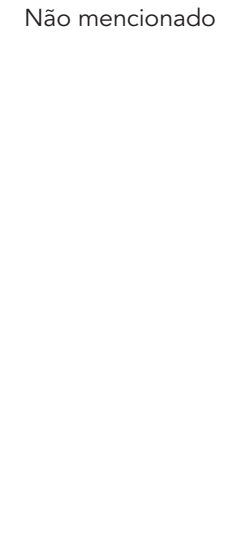 & $\begin{array}{c}\text { Revisão da } \\
\text { literatura; } \\
\text { opinião de } \\
\text { especialistas; } \\
\text { Técnica de } \\
\text { Delphi. Piloto } \\
\text { de } 5 \text { indicadores } \\
\text { que tiveram } \\
\text { os níveis de } \\
\text { consenso mais } \\
\text { altos, para avaliar } \\
\text { viabilidade, } \\
\text { confiabilidade e } \\
\text { validade } 38\end{array}$ & $\begin{array}{l}\text { Os especialistas } \\
\text { tinham que } \\
\text { responder se o } \\
\text { indicador deveria } \\
\text { ser incluído }\end{array}$ & 1721,38 \\
\hline
\end{tabular}

(continua) 
Tabela 3 (continuação)

\begin{tabular}{|c|c|c|c|c|c|c|c|c|c|}
\hline \multirow[t]{2}{*}{ Autor } & \multirow[t]{2}{*}{ Ano } & \multirow[t]{2}{*}{ Países } & \multirow{2}{*}{$\begin{array}{l}\text { Organi- } \\
\text { zações }\end{array}$} & \multirow[t]{2}{*}{ Ano } & \multirow{2}{*}{$\begin{array}{l}\text { Descrição/ } \\
\text { Objetivo(s) }\end{array}$} & \multicolumn{4}{|c|}{ Desenvolvimento } \\
\hline & & & & & & Modelo conceitual & $\begin{array}{l}\text { Métodos para } \\
\text { seleção e } \\
\text { validação }\end{array}$ & $\begin{array}{l}\text { Critérios para } \\
\text { seleção }\end{array}$ & $\begin{array}{l}\text { Quantidade de } \\
\text { indicadores * }\end{array}$ \\
\hline NSWTAG 27 & 2007 & Austrália & $\begin{array}{c}\text { NSWTAG } \\
\text { e CEC }\end{array}$ & 2007 & $\begin{array}{l}\text { Os indicadores } \\
\text { foram } \\
\text { desenvolvidos } \\
\text { como parte } \\
\text { da Política } \\
\text { Nacional de } \\
\text { Medicamentos } \\
\text { da Austrália }\end{array}$ & $\begin{array}{c}3 \text { dimensões: } \\
\text { seleção criteriosa, } \\
\text { escolha apropriada } \\
\text { e uso seguro } \\
\text { e efetivo de } \\
\text { medicamentos }\end{array}$ & $\begin{array}{l}\text { Revisão da } \\
\text { literatura; } \\
\text { consulta a } \\
\text { especialistas. } \\
\text { Piloto foi } \\
\text { realizado em } \\
31 \text { hospitais } \\
\text { de } 5 \text { estados } \\
\text { australianos, } \\
\text { para avaliar: } \\
\text { validade de face } \\
\text { e conteúdo; } \\
\text { mensurabilidade; } \\
\text { clareza das } \\
\text { especificações; } \\
\text { utilidade; e } \\
\text { comparabilidade }\end{array}$ & $\begin{array}{l}\text { Algoritmo para } \\
\text { seleção dos } \\
\text { indicadores } \\
\text { com base } \\
\text { nos critérios: } \\
\text { evidência de } \\
\text { uso ou validação } \\
\text { anterior; } \\
\text { evidência de } \\
\text { nível I ou ll, } \\
\text { recomendado } \\
\text { fortemente } \\
\text { por alguma } \\
\text { organização; } \\
\text { importância; } \\
\text { capacidade } \\
\text { de estar sob o } \\
\text { controle dos } \\
\text { prestadores; } \\
\text { mensurabilidade }\end{array}$ & 23 \\
\hline AlHW 25 & 2008 & Austrália & AlHW & 2008 & $\begin{array}{l}\text { A proposta foi } \\
\text { desenvolvida } \\
\text { por solicitação } \\
\text { do Ministério } \\
\text { da Saúde, como } \\
\text { instrumento } \\
\text { para apoiar e } \\
\text { monitorar as } \\
\text { reformas na } \\
\text { área de saúde, } \\
\text { além de permitir } \\
\text { a avaliação do } \\
\text { desempenho do } \\
\text { sistema de saúde }\end{array}$ & $\begin{array}{l}\text { Princípios de } \\
\text { organização dos } \\
\text { indicadores: } \\
\text { melhor saúde; } \\
\text { foco na prevenção; } \\
\text { acessibilidade; } \\
\text { alta qualidade } \\
\text { (cuidados } \\
\text { apropriados } \\
\text { e seguros); } \\
\text { integração e } \\
\text { continuidade; } \\
\text { cuidados centrados } \\
\text { no paciente; } \\
\text { eficiência; } \\
\text { sustentabilidade }\end{array}$ & $\begin{array}{l}\text { Levantamento } \\
\text { de indicadores } \\
\text { utilizados; } \\
\text { processo de } \\
\text { consulta a } \\
\text { especialistas } \\
\text { e vários } \\
\text { stakeholders }\end{array}$ & $\begin{array}{l}\text { Importância; } \\
\text { compreensibili- } \\
\text { dade; direciona- } \\
\text { mento para a } \\
\text { mudança; viabili- } \\
\text { dade; validade; } \\
\text { abrangência do } \\
\text { conjunto de indi- } \\
\text { cadores e outros }\end{array}$ & 7 \\
\hline
\end{tabular}

ACHS: The Australian Council on Healthcare Standards; AHRQ: Agency for Healthcare Research an Quality; AlHW: Australian Institute of Health and Welfare; CBO: Dutch Health Care Improvement Institute; CEC: Clinical Excellence Commission; CHCA: Child Health Corporation of America; CIHI: Canadian Institute for Health Information; CPSI: Canadian Patient Safety Institute; ESQH: European Society for Quality in Healthcare; CID-9-CM: Classificação Internacional de Doenças - 9ạ Revisão, com Modificação Clínica; IOM: Institute of Medicine; NACHRI: National Association of Children's Hospitals and Related Institutions; NSWTAG: New South Wales Therapeutic Advisory Group; OECD: Organization for Economic Co-operation and Development; PDI: indicadores de qualidade do cuidado pediátrico; PDSA: "plan, do, study, act"; PSI: indicadores de segurança do paciente; UTI: unidade de cuidados intensivos; WHA: Women's Hospitals Australasia; WHO/EURO: World Health Organization Regional Office for Europe.

* Somente o quantitativo de indicadores de segurança do paciente incluídos na revisão sistemática. 
pacientes, aos profissionais e ambiente, e que também promove essa noção".

Dois projetos apresentaram definição para indicador de segurança do paciente 14,24 . No estudo da AHRQ, os indicadores de segurança do paciente (PSI) são definidos como: "indicadores de qualidade específicos que também refletem a qualidade do cuidado nos hospitais, mas focam em aspectos da segurança do paciente. Especificamente, os PSI rastreiam problemas que os pacientes vivenciam como resultado da exposição ao sistema de saúde, e que são susceptiveis à prevenção, através de mudanças ao nível do sistema ou do prestador" 31. Para o projeto SimPatIE 24, os PSI são indicadores de qualidade que "direta ou indiretamente monitoram eventos adversos evitáveis".

O escopo do trabalho da AHRQ se restringiu à identificação de resultados do processo de cuidado potencialmente evitáveis, com base nos diagnósticos registrados nos bancos administrativos hospitalares codificados segundo a Classificação Internacional de Doenças - 9a Revisão, com Modificação Clínica (CID-9-CM). Já o projeto SimPatIE incluiu em sua proposta medidas sobre processos organizacionais que podem expor os pacientes a efeitos indesejáveis e medidas de resultado.

Nos projetos que abordam a segurança como uma dimensão da qualidade, sete apresentaram os modelos conceituais utilizados 15,17,22,25,27,28,30. Dois 15,30 organizaram os indicadores de acordo com as dimensões propostas pelo Instituto de Medicina (IOM) dos Estados Unidos 32: segurança, efetividade, cuidados centrados no paciente, oportunidade, eficiência e equidade (Tabela 3 ). O projeto de indicadores de saúde do Canadá 22 e a agência acreditadora Australian Council for Healthcare Standards (ACHS) 28,33 organizam os indicadores de acordo com as dimensões de avaliação do desempenho de seus respectivos sistemas nacionais de saúde. As dimensões segurança, efetividade, adequação, eficiência, acessibilidade, continuidade e competência/capacidade são comuns aos modelos do Canadá e Austrália. O modelo canadense inclui ainda a dimensão aceitabilidade e o australiano, as dimensões capacidade de resposta ("responsive") $\mathrm{e}$ sustentabilidade.

É interessante observar que o Australian Institute of Health and Welfare (AIHW), ao desenvolver sua proposta de indicadores de desempenho ${ }^{25}$, criou, com base no modelo conceitual australiano e nas prioridades nacionais de saúde, os seguintes eixos para organizar os indicadores: melhor saúde, foco na prevenção, acesso (cuidado equânime e oportuno), alta qualidade dos cuidados (adequados e seguros), integração e continuidade do cuidado, cuidados centrados no paciente, eficiência, sustentabilidade e equidade.

Outras duas diferentes categorizações são as do projeto PATH 17, que inclui as dimensões segurança, efetividade clínica, eficiência, orientação da equipe, governança ("responsive governance") e cuidados centrados no paciente; e a do projeto australiano, específica para o uso de medicamentos, a qual abrange a seleção criteriosa, a escolha apropriada e o uso seguro e efetivo de medicamentos 27 . Por fim, o projeto da OECD também definiu um modelo conceitual para o seu programa de indicadores, posteriormente à publicação de seus indicadores de segurança do paciente, com base nos modelos de seus paísesmembros, como o Canadá e a Austrália 34 .

Observou-se que os projetos utilizam uma variedade de termos para denominar as dimensões da qualidade, e algumas vezes as definições empregadas para cada uma delas se superpõem, o que ocasiona dificuldades de comparação. De modo geral, dimensões como aceitabilidade, capacidade de resposta ("responsive") e cuidados centrados no paciente reúnem em seu contexto um atributo comum relacionado ao atendimento das necessidades dos pacientes e respeito às suas preferências 17,32,33,34. De maneira semelhante, as dimensões continuidade, acessibilidade e oportunidade abrangem aspectos comuns relacionados à capacidade de o sistema de saúde atender de forma pronta às necessidades contínuas de saúde dos pacientes 22,32,33.

\section{- Métodos e critérios para seleção e validação dos indicadores}

Todos os projetos mencionam a revisão de informações sobre indicadores utilizados por programas de monitoramento nacionais e internacionais e/ou a revisão de literatura, para recuperar evidência científica sobre potenciais indicadores. Em oito projetos 16,17,18,22,25,26,27,30, obteve-se pouca informação sobre essas revisões. O projeto de desenvolvimento de indicadores para UTI pediátricas 30 estabeleceu uma "solicitação de proposta de indicadores” pública e nacional para possibilitar a participação de diferentes hospitais e outras organizações.

Outra característica comum aos 14 projetos foi a participação de grupos de especialistas. Em oito projetos $17,18,22,23,24,25,27,30$, o envolvimento desses profissionais ocorreu desde as fases iniciais do desenvolvimento dos indicadores, o que incluiu, em quatro projetos 17,22,24,25, a participação na definição dos modelos conceituais. Em oito projetos 21,22,23,25,27,30,31,35, observou-se o emprego de grupos multidisciplinares, com a 
participação de médicos, enfermeiros, farmacêuticos e/ou outros especialistas. Também houve menção à participação de representações de agências privadas e de governo, pesquisadores e/ ou gestores em nove projetos 16,21,22,23,24,25,26,27,30. E em seis $22,23,24,25,26,27$, a participação de consumidores por intermédio de organizações representativas. Oito projetos buscaram garantir a representatividade dos grupos participantes em relação a diferentes aspectos, tais como: localização geográfica, prática profissional ou perfil do hospital 21,22,23,25,26,30,31,35.

É interessante destacar a observação feita no projeto de indicadores para maternidades sobre as limitações encontradas para a revisão da literatura; estas se devem a diferentes níveis de conhecimento clínico e à diversidade de origens e interesses dos participantes 23. Embora essa diversidade tenha estabelecido a base para um amplo debate, ela também propiciou a existência de inconsistências na priorização e classificação dos indicadores. A equipe do projeto avalia que teria sido melhor se os grupos tivessem sido separados no início do trabalho e uma lista de indicadores fosse identificada pelos profissionais com experiência clínica. Assim, a opinião dos consumidores, epidemiologistas e outros profissionais seria ouvida na decisão final para seleção. No entanto, essa metodologia também implicaria o risco de que alguns indicadores altamente valorizados pelos participantes não-clínicos não fossem incluídos para seleção 23 .

Seis projetos $23,27,30,31,35,36$ mencionaram alguma avaliação adicional sobre os indicadores para subsidiar a análise pelos grupos de especialistas e a seleção dos indicadores. Nos dois projetos desenvolvidos pela AHRQ, a análise de dados de bancos administrativos foi efetuada para auxiliar a seleção e o refinamento das especificações dos indicadores 31,35 e também para explorar potenciais vieses e a relação entre eles 35 . $\mathrm{O}$ projeto PATH 36 realizou um inquérito em 11 países europeus para analisar a relevância dos indicadores e o trabalho necessário para a coleta dos dados. Embora analisados com cautela em virtude de vieses amostrais, os resultados foram considerados importantes para aliar a teoria à prática e também para facilitar a seleção dos indicadores. O projeto australiano de desenvolvimento de indicadores para maternidades 23 utilizou dados secundários para testar a robustez de alguns indicadores e para observar a sua prevalência, de modo a avaliar a inclusão destes no conjunto a ser selecionado. Teste de campo realizado em hospitais australianos auxiliou na seleção final do conjunto de indicadores sobre o uso de medicamentos 27 . O projeto de indicadores para UTIs pediátricas realizou um inquérito nacional pela Internet, para obter a aprovação dos sete candidatos finais a indicadores e levantar recomendações sobre eles, utilizando um instrumento elaborado pela Joint Commission, agência acreditadora americana 30 . Houve um total de 286 repostas representativas de 135 hospitais de pacientes agudos.

Todos os 14 projetos estabeleceram algum processo formal para a seleção dos indicadores. Foram utilizadas as seguintes técnicas de consenso: Método Delphi modificado (RAND/UCLA appropriateness method) 14,18,20, em três projetos; variações da técnica de Delphi 21,22,23, também em três; Grupo Nominal com modificações 15,17, em dois. Além da técnica Delphi, o projeto de indicadores de saúde do Canadá 22,29 realizou duas Conferências Nacionais de Consenso.

Houve significativa variabilidade nos termos empregados para indicar os critérios de seleção dos indicadores. Numa tentativa de classificação, aspectos mencionados pelos projetos foram agrupados em três grandes categorias: relevância e importância do indicador 15,16,17,18,22,23,24, $25,26,27,30,31,35$, força da evidência $15,17,18,22,23,24,25$, 27,30,31,35 (ou seja, validade e confiabilidade dos indicadores) e viabilidade 15,16,17,18,22,23,24,25, 26,27,30. Importância e relevância compreendem desde o significado atribuído por diferentes grupos representativos (profissionais, consumidores, políticos e outros) ao aspecto do cuidado medido, até o potencial da medida para promover melhorias e impactos positivos na saúde e a capacidade de prestadores e sistemas de saúde de atuar sob os resultados obtidos. Por sua vez, viabilidade abrange desde a análise sobre a disponibilidade de dados até a avaliação dos recursos necessários disponíveis para o desenvolvimento de fontes de dados e a manutenção dos sistemas de monitoramento.

Nove projetos 16,23,27,29,30,37,38,39,40 mencionaram a realização de testes-piloto; em três não se obteve informação sobre estes 16,29,30. A abrangência e os objetivos das análises apresentaram variações significativas. Em um projeto 37 , equipes de 13 UTIs americanas avaliaram a validade (construto e conteúdo) e a confiabilidade de potenciais indicadores desenvolvidos para estas unidades. Revisores independentes avaliaram os indicadores desenvolvidos para maternidades com o objetivo de analisar a sua utilidade e a sua validade estatística para monitorar a qualidade do cuidado 23. Para isso, utilizaram um método para pontuar os indicadores numa escala de 1 a 4 em 20 itens pré-selecionados, como, por exemplo, se "a dimensão da qualidade do indicador está descrita de modo apropriado". Estudo-piloto de cinco indicadores sobre o uso seguro de medicamentos foi realizado em hospitais canaden- 
ses para avaliar a viabilidade, a confiabilidade e a validade 38. Outro estudo-piloto foi realizado em trinta e um hospitais de cinco estados australianos para avaliar a validade de face e conteúdo, a mensurabilidade (em relação à coleta de dados), a clareza das especificações, a utilidade e a comparabilidade de candidatos a indicadores sobre $o$ uso de medicamentos 27. A implementação-piloto do projeto PATH foi realizada em 51 hospitais de seis países europeus com o objetivo de avaliar o trabalho para coleta dos dados, as eventuais necessidades de treinamento e outros recursos; auxiliar o refinamento dos indicadores e discutir estratégias para a implantação do projeto em larga escala 39 . O projeto da OECD realizou dois inquéritos para investigar a disponibilidade e a comparabilidade dos dados para construção dos indicadores entre os países participantes 40,41.

Mais recentemente, a AHRQ estabeleceu um projeto-piloto para avaliar a validade de critério dos PSI por meio da revisão de prontuários 42 .

\section{- Características dos indicadores de segurança do paciente}

Um total de 368 indicadores foi identificado. Destes, 83 foram excluídos: 47 por serem iguais; 18 por não apresentarem detalhes sobre as especificações, 16 por serem voltados para cuidados a pacientes externos e dois por serem indicativos de processos/estruturas específicos de alguns países. Restaram 285 indicadores (a lista completa está disponível com as autoras), dos quais, 160 (56,1\%) são indicadores de segurança do paciente apenas e 125 (43,9\%) foram classificados em mais de uma dimensão. A combinação mais freqüentemente encontrada foi segurança e efetividade (112; 89,6\%), ou seja, indicadores que medem tanto a segurança quanto a efetividade do cuidado. A maior concentração de indicadores foi na área de medicamentos (22,1\%). Mais da metade dos indicadores representa informações de resultado $(63,9 \%)$ (Tabela 4). A fonte dos dados não estava especificada para $62,1 \%$ dos indicadores, principalmente porque dois projetos 16,26 deixam para os hospitais a escolha da fonte de dados para a construção dos indicadores.

Todos os indicadores identificados nesta revisão possuem validade de face, atribuída por especialistas, e somente $24,5 \%$ (64) passaram por alguma validação adicional, durante a fase de desenvolvimento. Embora os projetos tenham buscado construir os indicadores com base na melhor evidência científica disponível ou na experiência de outros programas de monitoramento, foi observada uma variabilidade importante no grau e disponibilidade dessa evidência 14,17,18,19,20,23,24. A necessidade de análises e va- lidações adicionais foi indicada particularmente quando o uso dos indicadores se destina a comparações entre hospitais 14,20,21,27.

O desenvolvimento dos 20 indicadores de segurança do paciente pela AHRQ 14, em 2002, é considerado pioneiro (Tabela 5). Esse trabalho influenciou significativamente no desenvolvimento dos PSI do projeto da OECD 18 e do projeto SimPatIE 24. Juntos, os três projetos desenvolveram um total de 44 indicadores de segurança, 13 dos quais são originários do estudo da AHRQ e foram selecionados pela OECD e pelo projeto SimPatIE (Tabela 5). Após o desenvolvimento, os 20 PSI da AHRQ têm sido os mais estudados, utilizados em pesquisas, relatos públicos e comparações entre hospitais 3,4 . Resultados preliminares do teste sobre a validade de critério de cinco PSI 42 mostram variações nos seus valores preditivos positivos (percentual de casos identificados que realmente apresentam o evento) (Tabela 5). O National Quality Forum (NQF) 43, órgão americano que avalia indicadores mediante um processo formal de consenso, endossou cinco PSI da AHRQ para cuidados a pacientes adultos, listados na Tabela 5. Além desses, o NQF também endossou quatro indicadores de segurança pediátricos desenvolvidos pela AHRQ 20: puncionamento e laceração acidental; úlcera de decúbito; pneumotórax iatrogênico em não neonatos; e reação à transfusão 43 .

\section{Discussão}

Nesta revisão, foi observado o uso de diversos termos relacionados à qualidade e segurança do paciente com definições variadas. A polissemia tem caracterizado a área de segurança do paciente, o que levou a OMS a criar um grupo de trabalho, em 2005, para desenvolver uma taxonomia abrangente, recentemente publicada 2 . No entanto, ao conduzir esta revisão, verificou-se que esforços semelhantes vêm sendo empreendidos paralelamente, como o desenvolvimento pelo projeto SimPatIE 11 de um vocabulário para a área de segurança do paciente. Observa-se também que, embora os países e projetos internacionais busquem desenvolver seus modelos conceituais com base nos de outros projetos, há variações nos termos e definições adotados, o que dificulta as comparações.

Uma preocupação observada em todos os 14 projetos foi a de assegurar a viabilidade dos programas de monitoramento sem impor uma sobrecarga de custos e trabalho com a coleta de dados e a construção de novos sistemas de informação. A necessidade de garantir um equilíbrio razoável entre a viabilidade e a validade dos 
Tabela 4

Classificação dos indicadores por área clínica/setor de cuidado, nível da informação e fonte dos dados.

\begin{tabular}{|c|c|c|c|c|c|c|c|c|c|c|c|c|c|c|c|c|c|c|}
\hline \multirow{3}{*}{$\begin{array}{l}\text { Área clínica/Setor de } \\
\text { cuidado }\end{array}$} & \multirow{2}{*}{\multicolumn{2}{|c|}{$\begin{array}{l}\text { Quanti- } \\
\text { dade }\end{array}$}} & \multicolumn{6}{|c|}{ Nível da informação } & \multicolumn{10}{|c|}{ Fonte dos dados } \\
\hline & & & \multicolumn{2}{|c|}{ Estrutura } & \multicolumn{2}{|c|}{ Processo } & \multicolumn{2}{|c|}{ Resultado } & \multicolumn{2}{|c|}{ BDA } & \multicolumn{2}{|c|}{ Prontuário } & \multicolumn{2}{|c|}{ Inquérito } & \multicolumn{2}{|c|}{ Outra } & \multicolumn{2}{|c|}{$\begin{array}{l}\text { Não espe- } \\
\text { cificada }\end{array}$} \\
\hline & $\mathrm{n}$ & $\%$ & $n$ & $\%$ & $\mathrm{n}$ & $\%$ & $\mathrm{n}$ & $\%$ & $\mathrm{n}$ & $\%$ & $\mathrm{n}$ & $\%$ & $\mathrm{n}$ & $\%$ & $n$ & $\%$ & $n$ & $\%$ \\
\hline \multicolumn{19}{|l|}{ Adulto } \\
\hline Cirurgia/Anestesia & 32 & 11,2 & 0 & 0,0 & 6 & 2,1 & 26 & 9,1 & 12 & 4,2 & 0 & 0,0 & 0 & 0,0 & 0 & 0,0 & 20 & 7,0 \\
\hline Clínicos & 11 & 3,9 & 0 & 0,0 & 2 & 0,7 & 9 & 3,2 & 4 & 1,4 & 0 & 0,0 & 0 & 0,0 & & 0,0 & 7 & 2,5 \\
\hline UTI & 16 & 5,6 & 0 & 0,0 & 8 & 2,8 & 8 & 2,8 & 2 & 0,7 & 6 & 2,1 & 0 & 0,0 & 4 & 1,4 & 4 & 1,4 \\
\hline \multicolumn{19}{|l|}{ Pediatria } \\
\hline Cirurgia/Anestesia & 9 & 3,2 & 0 & 0,0 & 0 & 0,0 & 9 & 3,2 & 8 & 2,8 & 0 & 0,0 & 0 & 0,0 & 0 & 0,0 & 1 & 0,4 \\
\hline Clínicos & 2 & 0,7 & 0 & 0,0 & 0 & 0,0 & 2 & 0,7 & 1 & 0,4 & 0 & 0,0 & 0 & 0,0 & 0 & 0,0 & 1 & 0,4 \\
\hline UTI & 8 & 2,8 & 0 & 0,0 & 4 & 1,4 & 4 & 1,4 & 0 & 0,0 & 0 & 0,0 & 0 & 0,0 & 2 & 0,7 & 6 & 2,1 \\
\hline Cirurgia/Anestesia (ambos) & 28 & 9,8 & 0 & 0,0 & 9 & 3,2 & 19 & 6,7 & 2 & 0,7 & 0 & 0,0 & 0 & 0,0 & 0 & 0,0 & 26 & 9,1 \\
\hline Clínicos (ambos) & 22 & 7,7 & 2 & 0,7 & 3 & 1,1 & 17 & 6,0 & 5 & 1,8 & 1 & 0,4 & 0 & 0,0 & 0 & 0,0 & 16 & 5,6 \\
\hline UTI (ambos) & 6 & 2,1 & 1 & 0,4 & 2 & 0,7 & 3 & 1,1 & 1 & 0,4 & 0 & 0,0 & 0 & 0,0 & 0 & 0,0 & 5 & 1,8 \\
\hline Obstetrícia/Ginecologia & 26 & 9,1 & 0 & 0,0 & 4 & 1,4 & 22 & 7,7 & 6 & 2,1 & 0 & 0,0 & 0 & 0,0 & 5 & 1,8 & 15 & 5,3 \\
\hline Medicamentos & 63 & 22,1 & 2 & 0,7 & 45 & 15,8 & 16 & 5,6 & 4 & 1,4 & 28 & 9,8 & 1 & 0,4 & 0 & 0,0 & 30 & 10,5 \\
\hline Controle de infecção & 44 & 15,4 & 1 & 0,4 & 4 & 1,4 & 39 & 13,7 & 4 & 1,4 & 0 & 0,0 & 1 & 0,4 & 1 & 0,4 & 38 & 13,3 \\
\hline Outros & 18 & 6,3 & 5 & 1,8 & 5 & 1,8 & 8 & 2,8 & 2 & 0,7 & 0 & 0,0 & 5 & 1,8 & 3 & 1,1 & 8 & 2,8 \\
\hline Total & 285 & 100,0 & 11 & 3,9 & 92 & 32,3 & 182 & 63,9 & 51 & 17,9 & 35 & 12,3 & 7 & 2,5 & 15 & 5,3 & 177 & 62,1 \\
\hline
\end{tabular}

BDA: Banco de Dados Administrativos; UTI: unidade de cuidados intensivos.

indicadores é claramente abordada pelo projeto holandês 16 , ao ressaltar que a busca por um alto grau de validade pode elevar os custos e tornar os indicadores menos interpretáveis e transparentes, ao exigirem modelos de ajuste cada vez mais sofisticados. De modo semelhante, observouse a preocupação dos projetos em manter um conjunto pequeno de indicadores que possa ser mais facilmente gerenciado e utilizado de forma otimizada.

A necessidade de melhorar a qualidade dos dados e/ou incorporar novos dados e/ou desenvolver sistemas de informações foi abordada em oito projetos 22,23,24,25,31,35,39,41. Resultados do inquérito realizado pelo projeto PATH mostraram variações significativas na qualidade e disponibilidade dos dados entre os 11 países participantes 36. Dentre as questões levantadas, destacam-se o uso continuado da Classificação Internacional de Doenças - 9a Revisão, em vez da 10å; a falta relativa ou absoluta de codificação de diagnósticos secundários; problemas no registro dos dados refletindo formas de financiamento e a cultura; e o vínculo limitado entre os hospitais e os cuidados primários. O projeto utiliza a estratégia de dividir os indicadores em duas categorias: (a) os chamados "nuclea- res" são aqueles cujos dados estão geralmente disponíveis na maioria dos países europeus, são construídos com base na melhor evidência científica disponível e são considerados válidos; (b) os chamados "adaptados", que incluem indicadores para serem utilizados em situações específicas, devido à variabilidade na disponibilidade de dados, ao uso em hospitais de perfis diferenciados ou à sua validade. Por motivos semelhantes aos do PATH, o projeto SimPatIE não recomendou um único conjunto de PSI para uso em toda a Europa. O painel de especialistas classificou os indicadores desenvolvidos em quatro categorias: (1) exeqüíveis de forma imediata em todos os sistemas de saúde europeus; (2) exeqüíveis de forma imediata em partes dos sistemas de saúde europeus; (3) a implementação na Europa não é viável atualmente (uso futuro); (4) não apropriado como um PSI para a Europa. Por fim, o projeto holandês inclui indicadores que são de relato obrigatório pelos hospitais e outros que não são, em face da variabilidade na disponibilidade de dados 16 .

O conjunto de 285 indicadores identificados nesta revisão abrange um amplo espectro de cuidados prestados pelos hospitais a pacientes em diferentes grupos etários. Inclui áreas onde 
Tabela 5

Indicadores de segurança do paciente, por tipo, desenvolvidos pela AHRQ, OECD e SimPatIE.

\begin{tabular}{|c|c|c|c|c|}
\hline \multirow{2}{*}{$\begin{array}{l}\text { Indicadores } \\
\text { Títulos }\end{array}$} & \multirow[b]{2}{*}{ Tipo } & \multicolumn{3}{|c|}{ Organizações } \\
\hline & & AHRO & OECD & SimPatIE \\
\hline Avaliação da cultura de segurança do paciente no hospital & Proporção & & & $x$ \\
\hline Avaliação do risco de suicídio em pacientes esquizofrênicos & Proporção & & & $x$ \\
\hline Cirurgia em sítio errado & Proporção & & $x$ & $x$ \\
\hline Complicações anestésicas & Taxa & $x$ & $x$ & $x$ \\
\hline Compreensão dos pacientes sobre a sua medicação (transição do cuidado) & Taxa & & & $\mathrm{x}$ \\
\hline Corpo estranho deixado no corpo durante um procedimento & Taxa & $\mathrm{x}$ & $\mathrm{x}$ & $\mathrm{x}$ \\
\hline Deiscência de ferida pós-operatória & Taxa & $\mathrm{x}$ & & \\
\hline Desordem fisiológica e metabólica pós-operatória & Taxa & $\mathrm{x}$ & & $\mathrm{x}$ \\
\hline Embolia pulmonar ou trombose venosa profunda pós-operatórias * & Taxa & $x$ & $\mathrm{x}$ & $x$ \\
\hline Erro de medicação & Evento & & $x$ & $x$ \\
\hline Evento adverso relacionado a equipamento médico & Proporção & & $x$ & $x$ \\
\hline Falência respiratória pós-operatória & Taxa & $x$ & & $x$ \\
\hline Fratura de quadril pós-operatória & Taxa & $x$ & $x$ & $x$ \\
\hline Fratura de quadril ou queda em pacientes internados & Taxa & & $\mathrm{x}$ & $x$ \\
\hline Hemorragia ou hematoma pós-operatórios & Taxa & $\mathrm{x}$ & & $\mathrm{x}$ \\
\hline Higiene das mãos - conformidade da equipe com protocolos para o uso de jóias & Razão & & & $x$ \\
\hline Higiene das mãos - mensuração do consumo de álcool & Taxa & & & $\mathrm{x}$ \\
\hline Indicador de segurança do paciente composto (composição de PSIs selecionados) & Taxa & $x$ & & \\
\hline Infecção de ferida & Proporção & & $\mathrm{X}$ & $x$ \\
\hline Infecção de ferida pós-operatória & Proporção & & & $x$ \\
\hline Infecções selecionadas devidas aos cuidados de saúde * & Taxa & $x$ & $x$ & $x$ \\
\hline Desenvolvimento de cultura de segurança do paciente no hospital & Proporção & & & $x$ \\
\hline Monitoramento de efeitos colaterais relacionados ao tratamento antipsicótico & Proporção & & & $\mathrm{x}$ \\
\hline Monitoramento de eventos adversos relacionados a medicamentos (Electronic Trigger Tool) & Taxa & & & $x$ \\
\hline Óbitos de pacientes cirúrgicos com graves complicações tratáveis ("falência no resgate") ** & Taxa & $x$ & & $\mathrm{X}$ \\
\hline Óbitos em Grupos de Diagnósticos Relacionados (DRGs) de baixa mortalidade ** & Taxa & $\mathrm{x}$ & & $\mathrm{x}$ \\
\hline Pacientes com evento adverso devido a procedimento cirúrgico & Taxa & & & $x$ \\
\hline Pacientes informados pela equipe sobre a ocorrência de um evento adverso & Taxa & & & $\mathrm{x}$ \\
\hline Pacientes com eventos adversos & Taxa & & & $\mathrm{x}$ \\
\hline $\begin{array}{l}\text { Atitudes e resposta da equipe de profissionais após a ocorrência de eventos adversos } \\
\text { (inquérito - opinião dos pacientes) }\end{array}$ & Taxa & & & $x$ \\
\hline Pneumonia associada à ventilação & Razão & & $x$ & $\mathrm{x}$ \\
\hline Pneumotórax iatrogênico *,** & Taxa & $x$ & & $\mathrm{x}$ \\
\hline Problemas no nascimento (morte materna e outras morbidades maternas) & Proporção & & $\mathrm{X}$ & $\mathrm{x}$ \\
\hline 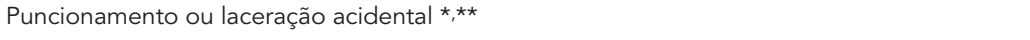 & Taxa & $x$ & $\mathrm{X}$ & $\mathrm{x}$ \\
\hline Quedas de pacientes & Taxa & & $\mathrm{X}$ & $x$ \\
\hline 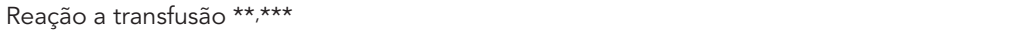 & Taxa & $x$ & $\mathrm{X}$ & $\mathrm{x}$ \\
\hline Sépsis pós-operatória * & Taxa & $x$ & $\mathrm{X}$ & $x$ \\
\hline Taxa de mortalidade hospitalar padronizada & Taxa & & & $\mathrm{x}$ \\
\hline Tipo de sangue errado & Proporção & & $\mathrm{X}$ & $x$ \\
\hline Trauma no nascimento - lesão ao neonato & Taxa & $\mathrm{x}$ & $\mathrm{X}$ & $\mathrm{x}$ \\
\hline Trauma obstétrico - parto cesáreo & Taxa & $x$ & $\mathrm{X}$ & $x$ \\
\hline Trauma obstétrico - parto vaginal com instrumentação \# & Taxa & $x$ & $\mathrm{x}$ & $x$ \\
\hline Trauma obstétrico - parto vaginal sem instrumentação \# & Taxa & $x$ & $\mathrm{X}$ & $x$ \\
\hline Úlcera de decúbito & Taxa & $\mathrm{x}$ & $\mathrm{x}$ & $\mathrm{x}$ \\
\hline
\end{tabular}

AHRQ: Agency for Healthcare Research and Quality; NQF: National Quality Forum; OECD: Organization for Economic Co-operation and Development; PSI: indicadores de segurança do paciente; SimPatIE: Safety Improvement for Patients in Europe.

* VPP - puncionamento e laceração acidental (91\%); pneumotórax iatrogênico (88\%); embolia pulmonar ou trombose venosa profunda pós-operatórias (48-83\%); infecções selecionadas devidas aos cuidados de saúde (61\%); e sépsis pós-operatória (41\%) 42;

** Indicadores da AHRQ endossados pelo NQF 43;

*** O projeto da OECD utiliza uma especificação diferente para o denominador deste indicador 53

\# O projeto da OECD agrega estes dois indicadores em um só 53 
a ocorrência de problemas na segurança é mais incidente, tais como medicamentos, infecção hospitalar e cuidados cirúrgicos 1,3,4,5.

Esta revisão também constatou o interesse pelo uso de bancos de dados administrativos para o monitoramento da qualidade e segurança dos cuidados de saúde 14,17,18,20. O projeto da OECD, reconhecendo que esses dados são os mais prontamente disponíveis para permitir comparações internacionais, elaborou um manual ${ }^{44}$ para adaptar os PSI da AHRQ à 10 a Revisão da Classificação Internacional de Doenças, utilizada por vários de seus países membros. No entanto, nem todos os indicadores têm como base a análise retrospectiva pautada em dados administrativos. Instrumentos padronizados para coleta de dados em pequenas amostras de prontuários podem permitir o monitoramento prospectivo, considerando a viabilidade para os hospitais e os custos envolvidos nesse processo 17,24,27,37,38. Por outro lado, a má qualidade no registro em prontuário, um constante empecilho para o monitoramento, pode ser contornada pela utilização de pequenos inquéritos como fonte de dados para a construção de indicadores 24,45.

Além da multiplicidade de conceitos e suas definições, durante esta revisão observou-se que os termos segurança, qualidade e suas outras dimensões ainda não estão claramente diferenciados, e os limites entre eles permanecem pouco claros. Talvez por isso, uma estratégia utilizada seja a construção de sistemas de monitoramento cujos indicadores medem várias dimensões da qualidade em conjunto 15,16,17,23,26,27. A utilização de um mesmo indicador para avaliar diferentes aspectos da qualidade do cuidado não extingue a necessidade de conceituações claras e padronizadas, pois parece evidente que ações diferenciadas são requeridas, por exemplo, para atuar sobre a eficiência e a segurança do cuidado.

\section{Limitações da revisão sistemática}

Esta revisão contém algumas limitações que precisam ser destacadas. Embora se tenha buscado ampliar o quantitativo de projetos utilizando a Internet para recuperar material não publicado, nem todas as possibilidades foram cobertas. Os sítios pesquisados se restringiram aos de organizações com representatividade nacional e internacional, o que pode ter excluído experiências regionais. A equação de busca eletrônica utilizada, apesar de abrangente, pode ter excluído processos de desenvolvimento de indicadores em áreas específicas. Documentos em alemão, francês, italiano, coreano e norueguês que apareceram na revisão não foram analisados, e iniciativas desses países podem ter sido excluídas por causa dos idiomas. Contudo, não se conhece outra revisão publicada sobre estratégias de desenvolvimento de indicadores de segurança do paciente e conclui-se que o presente trabalho conseguiu reunir um conjunto importante e abrangente de informações. Em adição, contemplou iniciativas de países que sabidamente destacam-se na área de segurança do paciente, como os Estados Unidos, a Austrália e o Canadá, além de organizações internacionais como a OECD e a OMS.

\section{Últimas considerações}

Os resultados obtidos nesta revisão reforçam a importância de desenvolver indicadores de segurança do paciente com base na melhor evidência científica disponível e de adaptá-los à realidade de cada país para garantir sua viabilidade. Esse processo deve considerar variações culturais e da prática clínica, a disponibilidade dos sistemas de informação e a capacidade de hospitais e sistemas de saúde para implementar programas de monitoramento da qualidade efetivos. A participação de diferentes grupos representativos nos processos de desenvolvimento de indicadores, como os consumidores, legitima esses processos e busca atender às diferentes necessidades e expectativas dos diversos atores envolvidos. Além disso, proporciona a construção de indicadores mais compreensíveis e factíveis.

A segurança do paciente é parte de um conceito mais amplo, a qualidade da atenção à saúde. A implantação de um programa global e multidimensional para avaliar e melhorar a qualidade dos cuidados de saúde deve ser uma prioridade dos governos em todos os níveis. Os projetos incluídos nesta revisão desenvolveram indicadores para permitir o monitoramento e a realização de comparações, visando a orientar o desenho de ações para a melhoria de qualidade. Para isso, investir no desenvolvimento de capacidades locais e nos sistemas de informação já existentes é uma condição essencial. Princípios que precisam nortear a construção dos programas de monitoramento para garantir a produção de informação para a tomada de decisões e estimular o compromisso de todos com a transparência nos serviços de saúde e a responsabilização com a melhoria de qualidade. 


\section{Resumo}

Foi realizada uma revisão sistemática para identificar as estratégias utilizadas no desenvolvimento de indicadores de segurança do paciente para hospitais de pacientes agudos. As fontes de dados utilizadas foram: MEDLINE, EMBASE, sítios na Internet e referências bibliográficas dos documentos selecionados. Foram incluídos 14 projetos de desenvolvimento de indicadores. $O$ uso de diversos termos relacionados à qualidade $e$ segurança do paciente foi observado com definições variadas. A revisão da literatura e a participação de especialistas e outras representações caracterizaram os projetos. Dos 285 indicadores identificados, 125 foram classificados em mais de uma dimensão da qualidade. A combinação mais freqüente foi segurança e efetividade. Identificou-se um número maior de indicadores sobre medicamentos, e a maioria representa informações de resultado. Observou-se a importância de considerar no desenvolvimento dos indicadores variações culturais, da prática clínica, a disponibilidade dos sistemas de informação e a capacidade de hospitais para implementar sistemas de monitoramento efetivos.

Segurança; Indicadores de Qualidade em Assistência à Saúde; Hospitalização

\section{Colaboradores}

C. S. D. Gouvêa e C. Travassos contribuíram na redação, revisão crítica do conteúdo e aprovação final da versão a ser publicada.

\section{Agradecimentos}

A Frederico Tadeu Oliveira Caixeiro pela participação na revisão e seleção dos resumos da revisão sistemática.

\section{Referências}

1. World Health Organization/World Alliance for Patient Safety. Summary of the evidence on patient safety: implications for research. The Research Priority Setting Working Group of the World Alliance for Patient Safety. Geneva: World Health Organization; 2008.

2. Runciman W, Hibbert P, Thomson R, Van Der Schaaf T, Sherman H, Lewalle P. Towards an International Classification for Patient Safety: key concepts and terms. Int J Qual Health Care 2009; 21:18-26.

3. Raleigh VS, Cooper J, Bremner SA, Scobie S. Patient safety indicators for England from hospital administrative data: case-control analysis and comparison with US data. BMJ 2008; 337:a1702.

4. Zhan C, Miller MR. Excess length of stay, charges, and mortality attributable to medical injuries during hospitalization. JAMA 2003; 290:1868-74.
5. Mendes W, Martins M, Rozenfeld S, Travassos C The assessment of adverse events in hospitals in Brazil. Int J Qual Health Care 2009; 21:279-84.

6. Allegranzi B, Storr J, Dziekan G, Leotsakos A, Donaldson L, Pittet D. The First Global Patient Safety Challenge "Clean Care is Safer Care": from launch to current progress and achievements. J Hosp Infect 2007; 65 Suppl 2:115-23.

7. Catalano K. JCAHO'S national patient safety goals 2006. J Perianesth Nurs 2006; 21:6-11.

8. Mainz J. Defining and classifying clinical indicators for quality improvement. Int J Qual Health Care 2003; 15:523-30.

9. McGlynn EA, Asch SM. Developing a clinical performance measure. Am J Prev Med 1998; 14 Suppl 3:14-21. 
10. Campbell SM, Braspenning J, Hutchinson A, Marshall M. Research methods used in developing quality indicators in primary care. Qual Saf Health Care 2002; 11:358-64

11. Kristensen S, Mainz J, Bartels P. A patient safety vocabulary. Safety Improvement for Patients in Europe. SimPatIE - Work Package 4; 2007. http://www.simpatie.org/Main/pf1175587453/ wp1175588035/wp1176820943 (acessado em 16/ Set/2007).

12. Joint Commission on Accreditation of Health Organizations. Primer on indicator development and application. Measuring quality in healthcare. Chicago: Joint Commission on Accreditation of Health Organizations; 1990.

13. Donabedian A. The quality of care: how can it be assessed? JAMA 1988; 260:1743-8.

14. Romano PS, Geppert JJ, Davies S, Miller MR, Elixhauser A, McDonald KM. A national profile of patient safety in U.S. hospitals. Health Aff (Millwood) 2003; 22:154-66.

15. Berenholtz SM, Dorman T, Ngo K, Pronovost PJ. Qualitative review of intensive care unit quality indicators. J Crit Care 2002; 17:1-12.

16. Berg M, Meijerink Y, Gras M, Goossensen A, Schellekens W, Haeck J, et al. Feasibility first: developing public performance indicators on patient safety and clinical effectiveness for Dutch hospitals. Health Policy 2005; 75:59-73.

17. Veillard J, Champagne F, Klazinga N, Arah OA, Guisset A-L. A performance assessment framework for hospitals: the WHO regional office for Europe PATH project. Int J Qual Health Care 2005; 17:487-96.

18. McLoughlin V, Millar J, Mattke S, Franca M, Jonsson PM, Somekh D, et al. Selecting indicators for patient safety at the health system level in OECD countries. Int J Qual Health Care 2006; 18 Suppl 1:14-20.

19. Scanlon MC, Mistry KP, Jeffries HE. Determining pediatric intensive care unit quality indicators for measuring pediatric intensive care unit safety. Pediatr Crit Care Med 2007; 8 Suppl 2:S3-10.

20. McDonald KM, Davies SM, Haberland CA, Geppert JJ, Ku A, Romano PS. Preliminary assessment of pediatric health care quality and patient safety in the United States using readily available administrative data. Pediatrics 2008; 122:e416-25.

21. Nigam R, MacKinnon NJ, U D, Hartnell NR, Levy AR, Gurnham ME, et al. Development of Canadian safety indicators for medication use. Healthc Q 2008; 11 (3 Spec No.):47-53.

22. Canadian Institute for Health Information. The Health Indicators Project: the next 5 years report from the Second Consensus Conference on Population Health Indicators; 2005. http:// secure.cihi.ca/cihiweb/disp Page.jsp?cw page=indicators_e\#consensus (acessado em 15/ Fev/2009).

23. Women's Hospitals Australasia. Supporting excellence in maternity care: The Core Maternity Indicators Project. http://www.safetyandquality.gov. au/internet/safety/publishing.nsf/Content/com pubs_InfoStrategy (acessado em 24/Fev/2009).
24. Kristensen S, Mainz J, Bartels P. Establishing a set of patient safety indicators. Safety Improvement for Patients in Europe. SImPatIE - Work Package 4; 2007. http://www.simpatie.org/Main/ pf1175587453/wp1175588035/wp1176820943 (acessado em 16/Set/2007).

25. Australian Institute of Health and Welfare. A set of performance indicators across the health and aged care system. http://www.aihw.gov.au/indicators/ index.cfm (acessado em 09/Jan/2009).

26. The Australian Council on Healthcare Standards. Australasian Clinical Indicator Report: 1998-2006. Determining the potential to improve quality of care: 8th edition. http://www.achs.org.au/cire ports (acessado em 25/Jan/2009).

27. NSW Therapeutic Advisory Group. Indicators for quality use of medicines in Australian hospitals. http://www.cec.health.nsw.gov.au/ (acessado em 19/Fev/2009).

28. The Australian Council on Healthcare Standards. ACHS Clinical Indicator Summary Guide 2004: an approach to demonstrating the dimensions of quality. Ultimo: Australian Council on Healthcare Standards; 2004.

29. Canadian Institute for Health Information. National Consensus Conference on Population Health Indicators. Final report. http://secure.cihi.ca/cihiweb/ dispPage.jsp?cw_page=indicators_e\#consensus (acessado em 15/Fev/2009).

29. National Association of Children's Hospitals and Related Institutions/The Child Health Corporation of America/Medical Management Planning, Inc. National pediatric practices \& measures. Focus on PICU. http://www.childrenshospitals.net/ (acessado em 02/Mar/2009).

30. McDonald KM, Romano PS, Geppert J, Davies SM, Duncan BW, Shojania KG, et al. Measures of patient safety based on hospital administrative data - the patient safety indicators. http://www.quali tyindicators.ahrq.gov/psi_download.htm (acessado em 09/Ago/2007).

31. Committee on Quality of Health Care in America, Institute of Medicine. Crossing the quality chasm: a new health system for the 21st century. Washington DC: National Academies Press; 2001.

32. National Health Performance Committee 2004. National report on health sector performance indicators 2003. http://www.aihw.gov.au/publi cations/index.cfm/title/10085 (acessado em 11/ Mar/2009).

33. Kelley E, Hurst J. Health Care Quality Indicators Project conceptual framework paper. OECD Health Technical Papers, 23. http://www.oecd.org/ health/hcqi (acessado em 09/Abr/2009).

34. McDonald KM, Romano PS, Davies S, Haberland C, Geppert J, Ku A, et al. Technical report measures of pediatric health care quality based on hospital administrative data: The Pediatric Quality Indicators. http://www.qualityindicators.ahrq.gov/pdi_down load.htm (acessado em 03/Dez/2008).

35. Veillard J, Guisset A-L, Garcia-Barbero M. Selection of indicators for hospital performance measurement: a report on the $3^{\text {rd }}$ and $4^{\text {th }}$ Workshop. http://www.euro.who.int/document/e84679.pdf (acessado em 09/Abr/2009). 
36. Pronovost PJ, Berenholtz SM, Ngo K, McDowell M, Holzmueller C, Haraden C, et al. Developing and pilot testing quality indicators in the intensive care unit. J Crit Care 2003; 18:145-55.

37. Nigam R, MacKinnon NJ, Nguyen T. Validation of Canadian medication-use safety indicators. http:// www.patientsafetyinstitute.ca/English/research/ cpsiResearchCompetitions/2005/Pages/MacKin non.aspx (acessado em 19/Dez/2008).

38. Groene O. Pilot test of the performance assessment tool for quality improvement in hospitals. Report on WHO Workshop. http://www.euro.who. int/document/hph/path_performanceass.pdf (acessado em 10/Mar/2009).

39. Mattke S, Kelley E, Scherer P, Hurst J, Lapetra MLG; the HCQI Expert Group Members. Health Care Quality Indicators Project. Initial indicators report. OECD Health Technical Papers, 22. http://www. oecd.org/health/hcqi (acessado em 09/Abr/2009).

40. Armesto SG, Lapetra MLG, Wei L, Kelley E; the Members of the HCQI Expert Group. Health Care Quality Indicators Project 2006. Data collection; update report. OECD Health Working Papers, 29. http://www.oecd.org/health/hcqi (acessado em 09/Abr/2009).

41. Lessons from the AHRQ PSI Validation Pilot Project. Slide presentation from the AHRQ 2008 Annual Conference (text version). http://www.ahrq. gov/about/annualmtg08/091008slides/Romano. htm (acessado em 09/Abr/2009).

42. National Quality Forum. National voluntary consensus standards for hospital care 2007: performance measures. A consensus report. http://www. qualityforum.org/Measures_List.aspx (acessado em 04/Mai/2009).

43. Drösler S. Facilitating cross-national comparisons of indicators for patient safety at the health-system level in the OECD countries. OECD Health Technical Papers, 19. http://www.oecd.org/health/hcqi (acessado em 09/Abr/2009).

44. WHO Regional Office for Europe. Performance assessment tool for quality improvement in hospitals. Indicators descriptions (core). http:// www.pathqualityproject.eu/ (acessado em 26/ Abr/2009).

45. The Australian Council on Healthcare Standards. Hospital-wide clinical indicators. Clinical indicator users' manual. Version 10 for use in 2007. http:// www.achs.org.au/pdf/HOSPITAL_WIDE_INDICA TORS_Example.pdf (acessado em 15/Mar/2009).
46. The Australian Council on Healthcare Standards. Gynaecology version 6. ACHS clinical indicator users' manual 2008. Version 6 for use in 2008. http:// www.ranzcog.edu.au/fellows/pdfs/Gynaecology_ Indicators.pdf (acessado em 10/Mar/2009).

47. The Australian Council on Healthcare Standards. Obstetrics version 6. ACHS clinical indicator users' manual 2008. Version 6 for use in 2008. http:// www.ranzcog.edu.au/fellows/pdfs/Obstetric_In dicators.pdf (acessado em 10/Mar/2009).

48. AHRQ Quality Indicators. Patient safety indicators: technical specifications. Version 3.2. http://www. qualityindicators.ahrq.gov/psi_download.htm (acessado em 15/Dez/2008).

50. Agency for Healthcare Research and Quality. Quality indicators. Patient Safety Quality Indicators Composite Measure Workgroup final report. http://www.qualityindicators.ahrq.gov/psi_down load.htm (acessado em 15/Dez/2008).

51. Dutch Health Care Inspectorate. Basic set of hospital performance indicators 2004. http://www. igz.nl/uk/supervision/ukpresind (acessado em 15/Dez/2008).

52. World Health Organization. 1st Workshop on Pilot Implementation of the Performance Assessment Tool for Quality Improvement in Hospitals. http:// www.euro.who.int/document/E84680.pdf (acessado em 10/Mar/2009).

53. Millar J, Mattke S; the Members of the OECD Safety Panel. Selecting indicators for patient safety at the health systems level in OECD countries. OECD Health Technical Papers, 18. http://www.oecd.org/ dataoecd/53/26/33878001.pdf (acessado em 09/ Abr/2009)

54. AHRQ Quality Indicators. Pediatric quality indicators: technical specifications. Version 3.2. http:// www.qualityindicators.ahrq.gov/psi_download. htm (acessado em 15/Dez/2008).

55. Agency for Healthcare Research and Quality. Pediatric Quality Indicators Composite Measure Workgroup final report. http://www.qualityindicators. ahrq.gov/pdi_download.htm (acessado em 15/ Dez/2008).

56. Kristensen S, Mainz J, Bartels P. Catalogue of Patient Safety Indicators. Safety Improvement for Patients in Europe. SImPatIE - Work Package 4. http://www.simpatie.org/Main/pf1175587453/ wp1175588035/wp1176820943 (acessado em 16/ Set/2007).

Recebido em 30/Nov/2009

Versão final reapresentada em 18/Mar/2010

Aprovado em 24/Mar/2010 